\title{
CARACTERIZAÇÃO E CINÉTICA DE SECAGEM DE GRÃOS DE QUINOA (Chenopodium quinoa Willd.)
}

\author{
V. M. B. MATSUMOTO ${ }^{1}$ e T. F. PÁDUA ${ }^{1}$ \\ ${ }^{1}$ Universidade Federal de São Carlos, Departamento de Engenharia Química \\ E-mail para contato: viviane-matsumoto@hotmail.com
}

RESUMO - A quinoa é um grão altamente nutritivo que pode ser utilizado para consumo animal ou humano, embora ele ainda seja limitado no Brasil devido ao alto custo do grão importado, apesar de o cultivo de quinoa no país ter potencial para crescer. No entanto, pouco se pesquisou sobre sua secagem para posterior armazenamento ou conservação, processo fundamental para se evitar perdas por ação microbiológica e garantir a qualidade do grão. $\mathrm{O}$ objetivo deste trabalho foi de realizar estudos preliminares sobre a cinética de secagem da quinoa e caracterizá-la fisicamente. $O$ alto desvio padrão das medidas feitas para 45 grãos dos três principais eixos W, T' e L indica a grande variabilidade dos tamanhos. Os valores de diâmetro da parte esférica, área superficial da semente, esfericidade e volume foram de $1,30 \mathrm{~mm}, 5,78 \mathrm{~mm}^{2}, 0,58$ e $1,30 \mathrm{~mm}^{3}$. O peneiramento mostra que a maior parte dos grãos de quinoa apresenta tamanho superior a $1 \mathrm{~mm}$. Medidas de área projetada e de perímetro praticamente não indicaram variação das medidas com a umidade do grão. As curvas de umidade em função do tempo de secagem em estufa foram construídas para temperatura de $30^{\circ} \mathrm{C}$ e apresentaram discrepâncias entre as amostras, o que pode indicar a necessidade de mapeamento da estufa e a interferência da espessura da placa de petri utilizada para armazenar cada amostra durante o processo.

\section{INTRODUÇÃO}

O cultivo da quinoa no Brasil ainda é recente, mas bastante promissor por se tratar de um grão adaptável, que oferece altos rendimentos mesmo em situações climáticas adversas (Tolaba et al., 2004; Gely \& Santalla, 2007). O consumo do grão no Brasil é limitado devido ao elevado custo do grão importado, à falta de informação por parte de consumidores e produtores e à baixa disponibilidade de locais de cultivo adaptados (Rocha, 2008).

Apesar de seu potencial para cultivo no Brasil, pouco se pesquisou sobre a secagem dos grãos para armazenamento ou mesmo na produção e conservação de sementes. A secagem é utilizada para reduzir a atividade da água no material, de modo que ocorram menos perdas do produto por ação microbiológica. A finalidade de tais estudos é, portanto, garantir a qualidade do grão para consumo e a da semente para futura semeadura, já que elas são colhidas em geral com 40 a $60 \%$ de umidade (Macedo et al., 1987) e devem ser armazenadas com no máximo 13\% (Silva, 1998).

Tendo o contexto mencionado em mente, o objetivo deste trabalho foi de desenvolver estudos preliminares para escolha de um método apropriado de secagem de grãos de quinoa. Os trabalhos foram iniciados com um estudo do método de umidificação mais apropriado e 
depois as características físicas dos grãos foram determinadas. A caracterização torna-se necessária para que se compreenda e se descreva com mais detalhes o processo de secagem. $\mathrm{O}$ presente trabalho também realizou ensaios de cinética de secagem em estufa a $30^{\circ} \mathrm{C}$ para contribuir com os conhecimentos sobre o processo.

\section{METODOLOGIA}

\subsection{Processo de Umidificação}

O método utilizado faz uso de um banho termostático (Arnost Jr. 1997), no qual uma resistência aquece o banho enquanto uma rede, acima do nível da água, contém os grãos que estão sendo umidificados em monocamada. $\mathrm{O}$ aparato experimental utilizado é mostrado na Figura 1.

Figura 1 - Desenho esquemático do banho termostático usado para umidificação.

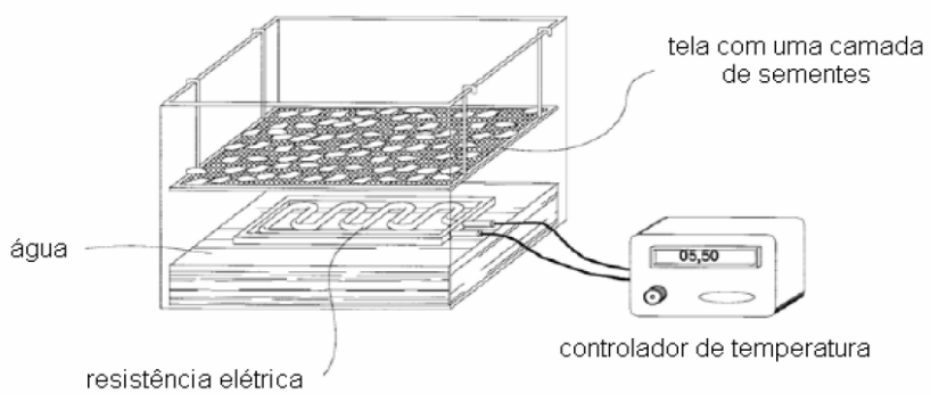

Fonte: Rizzi, 2008.

Numa primeira batelada, foram retiradas amostras de grãos a cada duas horas para que se observasse a partir de que momento a curva de umidade se estabilizaria. Amostras depois de 24 horas também foram retiradas. As amostras úmidas eram pesadas e em seguida colocadas em uma estufa a $105,0 \pm 3,0^{\circ} \mathrm{C}$ por um período de 24 horas; ao final do período eram novamente pesadas para que se encontrasse a massa dos grãos secos (BRASIL, 1980). A umidade em base seca é dada pela Equação 1.

$$
X_{b s}=\frac{m_{\text {umido }}-m_{\text {seca }}}{m_{\text {seca }}}
$$

\subsection{Processo de Secagem}

Para determinação da curva de secagem foi utilizada uma estufa da marca Tecnal (TE394/1 disponível no centro de secagem do DEQ-UFSCar) com abertura para o ar mas sem convecção forçada. A temperatura foi controlada em torno de $30^{\circ} \mathrm{C}$ e todo o processo foi feito em duplicata. Duas amostras de grãos foram recolhidas após o processo de umidificação em placas de petri de massa conhecida e pesadas. Elas seguiram então para a estufa. Nos primeiros 30 minutos de secagem, as amostras foram retiradas da estufa e pesadas a cada 5 
minutos. Nos 60 minutos seguintes, o procedimento foi repetido a cada 10 minutos. No próximo período de 60 minutos, elas foram retiradas e pesadas a cada 20 minutos. Por fim, nas quatro horas de secagem em estufa finais tal procedimento foi feito a cada 30 minutos. As amostras foram pesadas também depois de decorridas 24 horas de secagem.

\subsection{Caracterização dos grãos}

Foi feito peneiramento de uma porção de grãos de massa conhecida utilizando padrão de peneiras Tyler em conjunto com um sistema de vibração por 20 minutos. A partir dele foi possível obter um histograma da distribuição granulométrica dos sólidos e o diâmetro médio de Sauter (Ds), definido pela Equação 2, na qual $\mathrm{x}_{\mathrm{i}}$ é a fração mássica retida na peneira i e $\mathrm{D}_{\mathrm{i}}$ o diâmetro de abertura da peneira.

$D s=\frac{1}{\sum_{i=1}^{n} \frac{x_{i}}{D_{i}}}$

Foi utilizado um paquímetro digital Messen com duas casas de precisão para se obter as medidas nos três principais eixos das partículas - comprimento, espessura e largura. A Figura 2 representa os eixos medidos do elipsóide triaxial que corresponde aos grãos.

Figura 2 - Elipsóide Triaxial cujos eixos representam as medidas feitas com paquímetro.

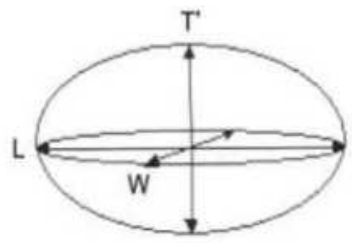

Fonte: Pereira, 2010

Ao total, 45 grãos, escolhidos aleatoriamente, foram utilizados para medição. A partir dessas medidas foi possível calcular o diâmetro da parte esférica (B), a área superficial da semente $(\mathrm{S})$, a esfericidade $(\varphi)$ e o volume $(\mathrm{V})$. Tais dimensões podem ser obtidas pelas Equações 3, 4, 5 e 6, respectivamente.

Obtiveram-se a área projetada e o perímetro através da análise de imagens capturadas por um microscópio Galai Macro Viewer por software Image Pró-Plus ${ }^{\circledR}$ a partir de amostras de grãos da população total. A redondeza pode ser calculada a partir da Equação 7, na qual p é o perímetro e $\mathrm{A}_{\mathrm{p}}$ é a área projetada (Arnosti, 1997).

$$
\begin{aligned}
B & =\left(W \cdot T^{\prime}\right)^{0,5} \\
S & =\frac{\pi \cdot B \cdot L^{2}}{2 \cdot L-B} \\
\varphi & =\frac{\sqrt[3]{\mathrm{W} \cdot T^{\prime} \cdot \mathrm{L}}}{\mathrm{L}}
\end{aligned}
$$




$$
\begin{gathered}
V=\frac{\pi \cdot B^{2} \cdot L^{2}}{6 \cdot(2 . L-B)} \\
R=\frac{p^{2}}{A_{p}} \cdot 4 \cdot \pi
\end{gathered}
$$

\section{RESULTADOS E DISCUSSÃO}

\subsection{Caracterização dos grãos secos}

Os resultados obtidos a partir das medições com o paquímetro são mostrados na Tabela 1. A partir dos elevados valores de desvio padrão para a área superficial e para o volume, pode-se inferir que existe grande variação de tamanho dos grãos. Os resultados obtidos para o peneiramento são mostrados na Figura 3. O diâmetro médio de Sauter calculado foi de $1,28 \mathrm{~mm}$. O diâmetro médio de Sauter e a curva de distribuição granulométrica mostram que a maior parte dos grãos de quinoa apresentaram tamanho superior a $1 \mathrm{~mm}$. Além disso, observa-se baixa esfericidade estimada, o que já era esperado, em razão do formato do grão (relativamente plano).

Tabela 1 - Resultados obtidos a partir do paquímetro.

\begin{tabular}{|c|c|c|c|c|c|c|c|}
\hline & W $(\mathrm{mm})$ & $\mathrm{T}^{\prime}(\mathrm{mm})$ & $\mathrm{L}(\mathrm{mm})$ & $\mathrm{B}(\mathrm{mm})$ & $\mathrm{S}\left(\mathrm{mm}^{2}\right)$ & $\varphi$ & $\mathrm{V}\left(\mathrm{mm}^{3}\right)$ \\
\hline Média & 0,52 & 0,89 & 0,92 & 1,30 & 5,78 & 0,58 & 1,30 \\
\hline Desvio padrão (\%) & 0,52 & 0,82 & 0,83 & 18,14 & 141,81 & 15,01 & 45,73 \\
\hline
\end{tabular}

Figura 3 - Distribuição granulométrica dos grãos.

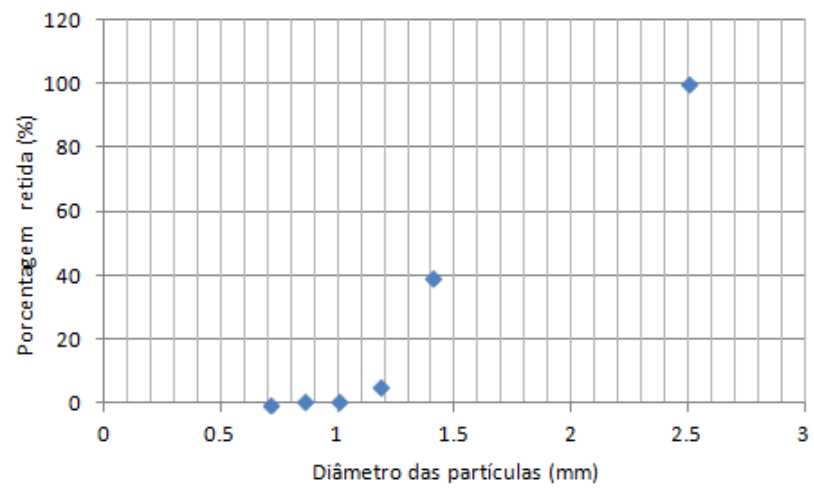

\subsection{Curva de umidificação e caracterização dos grãos úmidos}

A curva de umidificação é mostrada na Figura 4. A partir dela estabeleceu-se que os grãos deveriam ficar no banho por aproximadamente 4 horas para se atingir umidade de $30 \%$.

Ao longo do processo de umidificação, foram retirados alguns grãos para análise de imagens, a fim de que se avaliassem a variação do perímetro e da área projetada da quinoa com relação à umidade. Não houve aumento relevante dessas medidas em função da umidade, contrariando-se o que se esperava. Dentre as possíveis explicações estão a grande dispersão de dimensões da população, o pequeno número de grãos utilizados para cada imagem (devido 
ao alcance do microscópio) e o fato de que a imagem captura apenas o plano para T' e L, o que impossibilitou que a análise fosse feita para o eixo $\mathrm{W}$.

Figura 4 - Gráfico de curva de umidificação da quinoa em função do tempo.

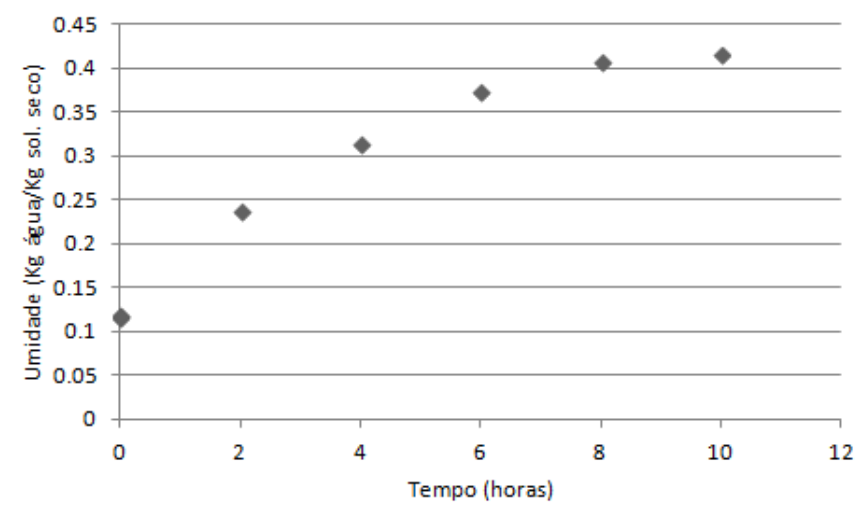

\subsection{Ensaios de secagem em estufa}

A curva obtida de umidade em função do tempo é mostrada na Figura 5. Como não se observa linearidade da umidade em função do tempo de secagem, não foi possível observar período de taxa constante de secagem nas curvas. Este comportamento é esperado, já que grãos de um modo geral apresentam mecanismo de transporte de massa interno ao grão. Assim, também se torna evidente que não houve excesso de umidificação, com formação de película externa de água.

Figura 5 - Umidade em base seca em função do tempo.

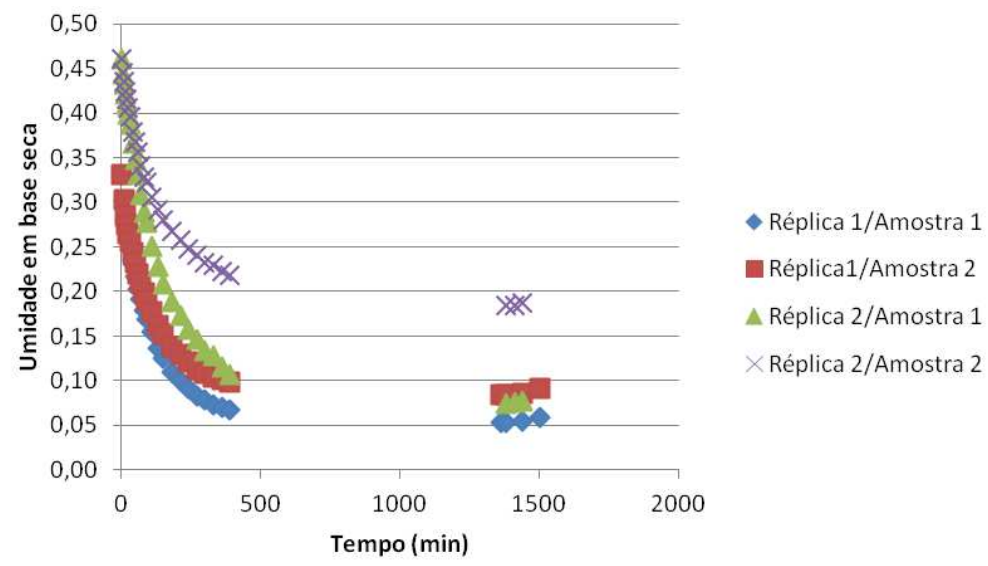

É possível notar que houve variação entre amostras da mesma réplica, embora os comportamentos das curvas sejam iguais e consistentes com o esperado. Como as duas amostras estavam juntas, sobre a mesma superfície metálica, supõe-se que houve variação de temperatura dentro da estufa e inteferência da espessura do vidro da petri. Além disso, o erro das medidas é bastante elevado, uma vez que durante a pesagem as amostras entravam em contato com a umidade do ar.

\section{CONCLUSÕES}


Os grãos de quinoa apresentaram distribuição larga de tamanhos em todos os comprimentos analisados (W, L e T') e a maior parte dos grãos apresentou tamanho superior a $1 \mathrm{~mm}$. Os valores de área projetada e perímetro encontrados não variaram significativamente em função da umidade dos grãos. O método de umidificação proposto foi eficiente para o grão, porém ele deve ser melhor averiguado em questão de reprodutibilidade. As curvas de secagem obtidas a $30^{\circ} \mathrm{C}$ apresentam o comportamento esperado, com a predominância dos efeitos de transporte de massa interno aos grãos durante a secagem. Apesar disso, é recomendado um mapeamento de temperatura da estufa e também o uso de placas de metal ao invés de petris de vidro para minimizar as diferenças de condução de calor entre amostras. Novas curvas devem ser feitas em diferentes temperaturas, para se analisar a influência dessa variável na secagem do grão.

\section{REFERÊNCIAS}

ARNOSTI Jr., S. Desenvolvimento de um secador transportador do tipo esteira com escoamento cruzado e caracterização de sementes de gramíneas. Tese de doutorado em eng. química, UFSCar, São Carlos, 1997.

BRASIL. Ministério da agricultura. Regras para análise de sementes. Brasília, SNDA/DNFV/CLV, 1980.

GELY M.C.; SANTALLA E.M. Moisture diffusivity in quinoa (Chenopodium quinoa Willd.) seeds: effect of air temperature and initial moisture content of seeds. J. Food Eng. 78: 1029-2033, 2009.

MACEDO G.A.R.; MARQUES NETO J.; BATISTA J. S. Secagem à sombra e ao sol de sementes de gramíneas forrageiras. Revista Brasileira de sementes, ano 9, 3: 29-37, Brasília, DR, 1987.

PEREIRA A.V. Caracterização e secagem de sementes de painço (Setaria itálica L.). Dissertação de mestrado, UFSCar, São Carlos, 2010.

RIZZI Jr. A.C. Secagem de sementes de gramíneas (Brachiaria brizantha) em leito fluidizado. Tese de doutorado em engenharia química, UFSCar, São Carlos, 2008.

ROCHA J. E. S. Seleção de genótipo de quinoa com características agronomias e estabilidade de rendimento no planalto central. Dissertação de mestrado em ciências agrárias, faculdade de agronomia e medicina veterinária, Universidade de Brasília, 2008.

SILVA W. R. Seed performance after exposure to high temperature. Sci. Agric., 55:102-109, número especial, Piracicaba, SP, 1998.

TOLABA M.P.; PELTZER M.; ENRIQUEZ N.; POLLIO M.L. Grain sorption equilibria of quinoa grains. J. Food Eng.; 61:365-371, 2004. 